\title{
RESEARCH
}

\section{THE EFFECT OF DEATH ANXIETY ON PERCEIVED PAIN LEVELS IN ELDERLY PATIENTS}

Turkish Journal of Geriatrics DOI: 10.31086/tjgeri.2020.160 2020; 23(2): 251-259

\section{- Nurgül ÖZDEMIR ${ }^{1}$ D \\ - Şengül KOCAMER ŞAHIN²}

CORRESPONDANCE

Şengül KOCAMER ŞAHIN

Gaziantep University, Faculty of Medicine, Psychiatry Department, Gaziantep, TURKEY.

Phone: +903423606060

e-mail: snglkcmr@hotmail.com

Received: November 28, 2019

Accepted: April 06, 2020

${ }^{1}$ Gaziantep University Health Sciences Faculty, Psychiatric Nursing, Gaziantep, TURKEY.

${ }^{2}$ Gaziantep University Faculty of Medicine, Psychiatry Department, Gaziantep, TURKEY.

\section{Abstract}

Introduction: The purpose of the present study was to examine the relationship between death anxiety-a significant issue for the elderly —and the pain levels in these individuals with increasing complaints of diseases with ageing.

Materials and methods: This descriptive cross-sectional study included geriatric patients who presented to the Gaziantep University Faculty of Medicine between 15.12.2018 and15.02.2019 for outpatient treatment and scored over 25 in the MiniMental test (MMT). Geriatric Pain Measure (GPM) and Turkish Death Anxiety Scale (TDAS) were used for assessment.

Results: Of the 315 individuals, aged 65 years and above, who participated in the study, $58.4 \%$ were in the $65-69$ age group with $52.7 \%$ males. A positive and statistically significant relationship was observed between GPM total score and TDAS total score, as well as its subscales, namely ambiguity of death, exposure to death and agony of death. A positive and statistically significant relationship was determined between the TDAS total score and GPM subscales, namely disengagement, pain intensity, pain at ambulation and pain during vigorous activities.

Conclusion: A positive relationship was observed between death anxiety and perceived pain in the elderly. The strongest relationship was determined between pain and anxiety because of the ambiguity of death. Many sociodemographic factors are related to death anxiety and the level of perceived pain. Therefore, death anxiety and pain may affect the quality of life for the elderly and should be promptly treated.

Keywords: Aged; Death; Anxiety; Pain Perception. 


\section{INTRODUCTION}

Ageing is an inevitable and irreversible physiological process that involves both physical and mental regression of an individual (1). World Health Organization considers individuals aged 65 years and above to be geriatric (1).

The world population continues to age rapidly owing to the increase in life expectancy, increase in birth rates, decrease in mortality rates and advancements in medical care (1). It is estimated that the geriatric population will increase from 524 million in 2010 to about 1.5 billion in 2050, with the highest increase occurring in developing countries (2). Notably, the elderly population in our country increases more rapidly compared with other age groups. The proportion of elderly population in Turkey will reach $10.2 \%$ in 2023, and Turkey will be among the countries with a 'too old' population (3).

Death anxiety refers to an emotion that develops from the awareness of nonexistence and of losing himself/herself and his/her world that was a part of one's life, and these thoughts form the foundation of all fears. Death anxiety can be evaluated as a multi-dimensional concept and can vary based on various factors, such as age, gender, religious beliefs, depression and other anxiety symptoms (4).

With the rapid increase in the elderly population worldwide and in Turkey, a corresponding increase has been observed in health problems related to old age, thereby making this topic significant. Age-related chronic diseases lead to a decrease in physical abilities as well as regressions in cognitive functions and daily life activities (5). Moreover, pain problems increase in the elderly alongside all the other factors (5). Elderly individuals frequently complain of acute and chronic pain. Despite most elderly individuals having several chronic diseases and using multiple medications, a pain assessment is not given sufficient importance in the elderly compared with the adult population in the society. However, society-based studies have revealed that the pain prevalence in individuals aged 60 years and above is twice that of the individuals aged below 60 years (6). Notably, untreated pain adversely affects the quality of life, resulting in physical or psychological problems besides increasing the rate of health care centre visits as well as healthcare expenses $(6,7)$. Nevertheless, healthcare professionals do not typically perform pain assessment and treatment despite the significant findings of pain prevalence in the elderly (6).

Even though literature survey revealed that most studies focussed on factors increasing anxiety and a positive relationship was observed between anxiety and perceived pain (8), we could find no study that focussed on establishing a connection with the concept of pain, which is a critical issue for the elderly. The present study has been conducted to determine whether death anxiety in the elderly affects their pain level, and it is hoped that the study findings shall pave the way for future studies and treatment applications.

\section{MATERIALS AND METHODS}

This descriptive study analysed the effect of death anxieties on pain levels in elderly individuals aged 65 years and above. Overall, 315 geriatric patients who presented to the Geriatrics Polyclinic of the Gaziantep University Faculty of Medicine for outpatient treatment between 15.12.2018 and 15.02.2019 were included in the study.

The purpose of the study was explained to the elderly participants, and they were informed that participation was entirely voluntary, and they could opt out whenever they wished to do so. Subsequently, they were asked to fill in the 'Informed Consent Form,"Personal Information Form,' as well as the Turkish Death Anxiety Scale (TDAS) and the Geriatric Pain Measure (GPM).

Written approvals were obtained from the Gaziantep University Clinical Research Ethics Committee and the Ministry of Health of the hospital where the study wasconducted. Participants included in the study were informed 
regarding the study, and oral and written consents were obtained from those who accepted to participate.

\section{Data Acquisition Tools:}

\section{Standardised Mini-Mental Test}

Standardised Mini-Mental Test (SMMT) is a scale used for assessing cognitive functions, identifying dementia and determining its severity, and can be applied by doctors, nurses and psychologists after a short training. The best threshold value was determined as 25/26 during a study conducted to assess the validity of the test in diagnosing Alzheimer type dementia, whereas it was observed that a threshold value of $23 / 24$ was accepted as an indication that SMMT has high sensitivity and specificity for diagnosing light dementia in the elderly Turkish population. SMMT was first performed on all individuals who participated in the study, and those with a score of above 25 were included (9).

\section{Turkish Death Anxiety Scale}

The TDAS developed by Sarikaya and Baloglu is a five-point Likert type scale comprising 20 items. Scale scores vary between 0 to 100 , and high scores indicate high death anxiety (10). Its subscales are Ambiguity of Death (AmD), Exposure to Death (ETD) and Agony of Death (AgD). The first component of the scale, AmD, concentrates on the unknown or unpredictable nature of death. ETD covers encountering dead, death or dying in the form of seeing, watching, talking, reading about or visiting. AgD component seems to elicit the fear of suffering as a result of death or dying.

\section{Geriatric Pain Measure}

GPM is a 24-item multi-dimensional scale developed by Ferrell BA et al. GPM is an easily applicable scale developed for outpatient geriatric individuals. The scale comprises five dimensions, namely disengagement (D), pain intensity (PI), pain at ambulation (PA), pain during vigorous activities (PVA) and pain during other activities (PDOA). The scale includes three open-ended questions on pain. The total score is calculated by summing up the 'Yes' answers and varies between 0-42. The GPM defines the pain of patients and evaluates the resulting physical, emotional, cognitive and behavioural responses. The scale contains several components that evaluate the effects of pain in the daily lives of patients to develop coping strategies and define various factors, such as the location, intensity and characteristic of the pain (7). Reliability and validity studies for this scale have been documented in Turkish (11)

\section{Statistical Analysis}

The quantitative variables were indicated using centralisation and variance measurements namely mean \pm SD. The internal consistencies of the scale were evaluated using Cronbach's alpha. ANOVA t-test was used to assess the behavioural differences of group mean values when normality and equal distribution assumptions are met, whereas nonparametric tests, such as Kruskal-Wallis H Test (group number $>2$ ) and Mann-Whitney $U$ test (group number=2), were performed for the other cases. Spearman's Rank Correlation test was used for measuring the strength and direction of the relationship between two continuous variables. Statistical significance was determined as $p=0.05$ for all cases. Statistical analyses were performed using IBM SPSS (Statistics for Windows, Version 21.0, Armonk, NY, IBM Corp).

\section{RESULTS}

\section{Descriptive Results}

Of the 315 geriatric individuals, 58.4\% were in the 65-69 years age group, $52.7 \%$ were males, $85.4 \%$ were married, $50.2 \%$ were literate, $79 \%$ were unemployed and $92.1 \%$ were living with their family. It was also determined that $23.2 \%$ had chronic cardiovascular disease, $45.4 \%$ had chronic diabetes, $37.1 \%$ had chronic hypertension and $7 \%$ had other chronic diseases (Table 1).

\section{SMMT, TDAS and GPM Results}

SMMT mean value was determined as $26.61 \pm$ 1.28 . 
TDAS total score mean value was determined as $30.41 \pm 19.83$. Upon subscale assessment, AgD was determined as $5.55 \pm 3.31$, AmD as $15.77 \pm$ 10.42 and ETD as $9.1 \pm 7.47$.

GPM total score mean value was determined as $53.09 \pm 25.36$. Upon subscale assessment, D was determined as $27.98 \pm 15.43$, PI as $11.64 \pm 4.87$, PDOA as $6.48 \pm 4.31, \mathrm{PA}$ as $6.2 \pm 3.94$ and PVA as $3.61 \pm 2.52$.

\section{TDAS and Subscales; GPM and Subscales} Correlation Results

A positive and statistically significant relationship was observed between GPM total score and TDAS total, as well as its subscales AmD, ETD and AgD ( $p<0.05)$ (Table 2).

A positive and statistically significant relationship was observed between TDAS total score and GPM total score, as well as its subscales $D, P I$, PDOA, PVA and PA ( $p<0.05)$ (Table 2).

Comparative Results for the TDAS Scale Based on Sociodemographic Characteristics of

\section{Patients}

A statistically significant difference was observed between education level and the subscale ETD $(p<0.05)$. Subscale score decreased with increasing level of education.

The mean value of TDAS total score and the mean values for subscales $A D, E T D$ and $A C$ were statistically significantly higher for female participants $(p<0.05)$. (Table 3 )

No statistically significant difference was observed between the mean value of TDAS total score and age ( $p>0.05)$.

Comparative Results for the GPM Scale Based on Sociodemographic Characteristics of Patients

A statistically significant difference was determined between the education levels of the elderly and the GPM total score mean value and the mean values of subscales $(p<0.05)$. Scale scores decreased with increasing level of education.

Table 1. Distribution of the Socio-Demographic Characteristics of the Elderly.

\begin{tabular}{|r|r|r|}
\hline \multicolumn{1}{|l|}{ Characteristics } & N & \% \\
\hline Age & & 58.4 \\
\hline $65-69$ & 184 & 26.3 \\
\hline $70-74$ & 83 & 15.2 \\
\hline Male & 48 & 52.7 \\
\hline Gender & & 47.3 \\
\hline Female & 166 & 14.6 \\
\hline Marital Status & 149 & 85.4 \\
\hline Single & & 50.2 \\
\hline Earried & 46 & 38.4 \\
\hline Illiterate & 269 & 11.4 \\
\hline Primary School - Secondary School & & \\
\hline High School - University & 158 & 7.9 \\
\hline Living With Someone & 121 & 92.1 \\
\hline Alone & 36 & \\
\hline
\end{tabular}


Table 2. Correlations between Turkish Death Anxiety Scale (TDAS), Geriatric Pain Measure (GPM).

\begin{tabular}{|c|c|c|c|c|c|c|c|c|c|c|}
\hline & 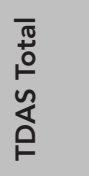 & 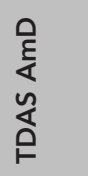 & $\begin{array}{l}0 \\
0 \\
4 \\
n \\
0 \\
0\end{array}$ & 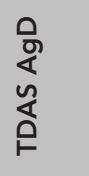 & $\begin{array}{l}\bar{\pi} \\
\text { D艹 } \\
\sum_{0}^{+}\end{array}$ & $\sum_{0}^{0}$ & $\sum_{0}^{\overline{1}}$ & 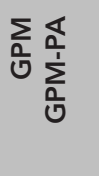 & $\frac{1}{\sum_{0}^{1}}$ & $\begin{array}{l}\varangle \\
\text { ○ } \\
0 \\
\sum_{0}^{1} \\
0\end{array}$ \\
\hline TDAS Total & 1 & & & & & & & & & \\
\hline TDAS AmD & $0.97 *$ & 1 & & & & & & & & \\
\hline TDAS ETD & $0.91 *$ & $0.8^{*}$ & 1 & & & & & & & \\
\hline TDAS-AgD & $0.84^{\star}$ & $0.8^{*}$ & $0.66^{*}$ & 1 & & & & & & \\
\hline GPM total & $0.3^{*}$ & $0.3^{*}$ & $0.28^{*}$ & $0.23^{\star}$ & 1 & & & & & \\
\hline GPM-D & $0.33^{\star}$ & $0.32^{\star}$ & $0.29^{*}$ & $0.27^{\star}$ & $0.94^{\star}$ & 1 & & & & \\
\hline GPM-PI & $0.17^{*}$ & $0.18^{\star}$ & $0.15^{\star}$ & 0.1 & $0.79 *$ & $0.64^{*}$ & 1 & & & \\
\hline GPM-PA & $0.19 *$ & $0.16^{*}$ & $0.22^{\star}$ & $0.14^{\star}$ & $0.71 *$ & $0.55^{\star}$ & $0.58^{\star}$ & 1 & & \\
\hline GPM-PVA & $0.23^{\star}$ & $0.22^{\star}$ & $0.23^{\star}$ & $0.12^{\star}$ & $0.67 *$ & $0.51^{\star}$ & $0.56^{*}$ & $0.52^{\star}$ & 1 & \\
\hline GPM-DOA & $0.24^{*}$ & $0.23^{\star}$ & $0.24^{*}$ & $0.17^{*}$ & $0.84^{*}$ & $0.7^{*}$ & $0.74^{\star}$ & $0.67 *$ & $0.65^{\star}$ & 1 \\
\hline
\end{tabular}

Disengagement (D), pain intensity (PI), pain at ambulation (PA), pain during vigorous activities (PVA), pain during other activities (PDOA), Ambiguity of Death (AmD), Exposure to Death (ETD) and Agony of Death (AgD).

A statistically significant difference was observed between age and GPM total score mean value, as well as the mean value of total score and the mean values of subscales $(p<0.05)$. Scale scores increased with increasing age. (Table 4).

No statistically significant difference was observed between the mean value of TDAS total score and marital status ( $p>0.05)$

\section{DISCUSSION}

Notably, pain problems increase with ageing (6), and anxiety plays a crucial role in increasing the level of perceived pain clinically (8). Even though some studies have indicated that death anxiety decreases with ageing, several large-scale studies have reported that death anxiety increases with age (12). Death anxiety significantly affects the lives of the elderly. The present study did not select healthy participants but those who presented to the polyclinic with medical conditions, not to measure the death anxiety intensity in the elderly but to examine its relationship with sociodemographic factors and pain. Our study results concluded that death anxiety and perceived pain are weakly correlated at a statistically significant level. Moreover, it was observed that several sociodemographic factors are related to death anxiety and the level of perceived pain. Study results were grouped and discussed under different titles.

\section{Relationship between Death Anxiety and Pain Levels}

Anxiety increases the perception of pain, especially in individuals with high anxiety and sensitivity (13). Expectedly, death anxiety can increase pain perception, like the other forms 
Table 3. Comparison of Mini Mental Test (MMT), Turkish Death Anxiety Scale (TDAS) in terms of Sociodemographic Characteristics.

\begin{tabular}{|c|c|c|c|c|c|}
\hline & \multicolumn{5}{|c|}{$\begin{array}{c}\text { Mean (x)-Std (ss) } \\
\text { Min-Max }\end{array}$} \\
\hline & MMT & TDAS_AmD & TDAS ETD & TDAS_AgD & TDAS_Total \\
\hline \multicolumn{6}{|l|}{ Literacy } \\
\hline Illiterate (158) & $26.34 \pm 1.1$ & $17.11 \pm 10.94$ & $10.03 \pm 7.69$ & $5.92 \pm 3.34$ & $33.06 \pm 20.67$ \\
\hline Primaryschool (121) & $26.64 \pm 1.29$ & $14.45 \pm 9.81$ & $8.35 \pm 7.11$ & $5.19 \pm 3.33$ & $27.98 \pm 18.81$ \\
\hline $\begin{array}{l}\text { High School - } \\
\text { University (36) }\end{array}$ & $27.67 \pm 1.41$ & $14.31 \pm 9.49$ & $7.53 \pm 7.29$ & $5.11 \pm 3.02$ & $26.94 \pm 18.26$ \\
\hline $\mathrm{P}$ & $<0.001$ & 0.103 & 0.07 & 0.145 & 0.107 \\
\hline \multicolumn{6}{|l|}{ Alcohol } \\
\hline Yes (15) & $26.53 \pm 1.06$ & $14.07 \pm 9.59$ & $5.93 \pm 6.23$ & $5.67 \pm 3.24$ & $25.67 \pm 16.79$ \\
\hline No (300) & $26.61 \pm 1.29$ & $15.85 \pm 10.47$ & $9.26 \pm 7.5$ & $5.54 \pm 3.32$ & $30.65 \pm 19.96$ \\
\hline $\mathrm{P}$ & 0.826 & 0.656 & 0.089 & 0.688 & 0.044 \\
\hline \multicolumn{6}{|l|}{ Gender } \\
\hline Male (166) & $26.74 \pm 1.27$ & $11.61 \pm 8.96$ & $6.36 \pm 6.05$ & $4.41 \pm 3.07$ & $22.38 \pm 16.55$ \\
\hline Female (149) & $26.46 \pm 1.27$ & $20.4 \pm 9.99$ & $12.15 \pm 7.73$ & $6.82 \pm 3.12$ & $39.36 \pm 19.38$ \\
\hline $\mathrm{P}$ & 0.027 & $<0.001$ & $<0.001$ & $<0.001(\mathrm{~m})$ & $<0.001$ \\
\hline \multicolumn{6}{|l|}{ Smoking } \\
\hline Yes (98) & $26.59 \pm 1.23$ & $13.54 \pm 9.17$ & $7.59 \pm 6.68$ & $4.95 \pm 3.2$ & $26.08 \pm 17.44$ \\
\hline No (217) & $26.61 \pm 1.3$ & $16.77 \pm 10.8$ & $9.78 \pm 7.71$ & $5.82 \pm 3.34$ & $32.37 \pm 20.56$ \\
\hline $\mathrm{P}$ & 0.953 & 0.02 & 0.02 & 0.034 & 0.014 \\
\hline
\end{tabular}

of anxiety. When considered conversely, death anxiety was determined to be statistically significantly higher in patients with fibromyalgia compared with the control group (14). Notably, the disengagement scale was observed to have the strongest relationship with death anxiety when correlations were examined. Our study observed death anxiety to be directly proportional to pain. Notably, a clear relationship exists between pain anxiety and mobility. A study found that death anxiety significantly predicted symptom severity. Even though the strongest relationship with pain was observed in the AmD subscale, theorists consider intolerance of uncertainty and anxiety sensitivity to be conceptually similar (15). Therefore, AmD may indicate high anxiety and pain.

\section{Relationship between Death Anxiety and Sociodemographic Data}

Death anxiety was determined to be inversely related to education level, health status and having social support. Generally, high education level may act as a protective factor against anxiety and depression (16).

Nonetheless, a relationship could not be determined between age and death anxiety. Typically, death anxiety peaks at approximately 20 years of age in males and females (17). However, death anxiety decreases with age in general (12). Because all patients included in our study were above the age of 65 years, observing no differences among the age groups was an expected result. Notably, a second peak occurs at age 50 years for females, with anxiety disorders observed more 
Table 4. Comparison of Turkish Death Anxiety Scale (TDAS) in terms of Sociodemographic Characteristics.

\begin{tabular}{|c|c|c|c|c|c|c|}
\hline \multirow{3}{*}{\begin{tabular}{|l} 
\\
Education
\end{tabular}} & \multicolumn{5}{|c|}{$\begin{array}{l}\text { Avg (x)-Std (ss) } \\
\text { Min-Max }\end{array}$} & \multirow[b]{3}{*}{ GPM total } \\
\hline & \multicolumn{5}{|c|}{ Geriatric Pain Measure (GPM) Sub-Scales } & \\
\hline & GPM-D & GPM -PI & GPM-PDOA & GPM-PVA & GPM-PA & \\
\hline Illiterate & $31.53 \pm 13.59$ & $13.12 \pm 4.13$ & $7.61 \pm 4.17$ & $3.86 \pm 2.54$ & $6.9 \pm 3.74$ & $59.73 \pm 22.44$ \\
\hline Primary School & $25.14 \pm 16.22$ & $10.72 \pm 4.95$ & $5.39 \pm 4.18$ & $3.48 \pm 2.46$ & $5.53 \pm 4.04$ & $47.86 \pm 26.13$ \\
\hline $\begin{array}{r}\text { High School - } \\
\text { University }\end{array}$ & $21.95 \pm 16.84$ & $8.2 \pm 5.23$ & $5.16 \pm 4.08$ & $2.98 \pm 2.57$ & $5.36 \pm 4.0$ & $41.58 \pm 27.2$ \\
\hline $\mathrm{P}$ & $<0.001$ & $<0.001$ & $<0.001$ & 0.14 & 0.004 & $<0.001$ \\
\hline \multicolumn{7}{|l|}{ Alcohol } \\
\hline Yes & $12.22 \pm 13.79$ & $9.84 \pm 5.23$ & $3.33 \pm 4.1$ & $2.86 \pm 2.24$ & $3.33 \pm 4.0$ & $29.83 \pm 22.98$ \\
\hline No & $28.77 \pm 15.1$ & $11.73 \pm 4.84$ & $6.63 \pm 4.26$ & $3.65 \pm 2.53$ & $6.34 \pm 3.89$ & $54.26 \pm 24.94$ \\
\hline $\mathrm{P}$ & $<0.001$ & 0.125 & 0.005 & 0.234 & 0.004 & 0.001 \\
\hline \multicolumn{7}{|l|}{ Gender } \\
\hline Male & $22.67 \pm 15.1$ & $10.41 \pm 5.22$ & $5.32 \pm 4.29$ & $45.31 \pm 10.51$ & $5.51 \pm 4.12$ & $44.89 \pm 25.73$ \\
\hline Female & $33.9 \pm 13.57$ & $13.0 \pm 4.04$ & $7.76 \pm 3.96$ & $45.11 \pm 9.3$ & $6.96 \pm 3.6$ & $62.23 \pm 21.61$ \\
\hline $\mathrm{P}$ & $<0.001$ & $<0.001$ & $<0.001$ & $p=0.75$ & 0.003 & $<0.001$ \\
\hline \multicolumn{7}{|l|}{ Smoking } \\
\hline Yes & $23.41 \pm 15.72$ & $10.73 \pm 4.65$ & $5.44 \pm 4.21$ & $3.5 \pm 2.58$ & $5.83 \pm 3.9$ & $46.65 \pm 25.74$ \\
\hline No & $30.04 \pm 14.88$ & $12.04 \pm 4.92$ & $6.94 \pm 4.27$ & $3.66 \pm 2.5$ & $6.36 \pm 3.96$ & $56.0 \pm 24.7$ \\
\hline $\mathrm{P}$ & 0.001 & 0.004 & 0.003 & 0.619 & 0.151 & 0.003 \\
\hline \multicolumn{7}{|l|}{ Age } \\
\hline $65-69(134)$ & $25.24 \pm 15.56$ & $10.36 \pm 5.13$ & $5.6 \pm 4.37$ & $3.26 \pm 2.46$ & $5.37 \pm 4.12$ & $47.26 \pm 25.82$ \\
\hline 70-74 (83) & $32.09 \pm 15.38$ & $13.31 \pm 3.86$ & $7.25 \pm 4.09$ & $4.07 \pm 2.45$ & $6.94 \pm 3.61$ & $60.62 \pm 23.41$ \\
\hline $75+(48)$ & $31.39 \pm 12.85$ & $13.64 \pm 3.83$ & $8.48 \pm 3.5$ & $4.16 \pm 2.71$ & $8.08 \pm 2.77$ & $62.43 \pm 20.53$ \\
\hline $\mathrm{P}$ & 0.002 & $<0.001$ & $<0.001$ & 0.014 & $<0.001$ & $<0.001$ \\
\hline
\end{tabular}

in females than males (18). Our study observed higher death anxiety in females compared with males.

Death anxiety was higher in patients with chronic diabetes, chronic hypertension or chronic coronary diseases. Cardiovascular diseases are the primary causes of death for diabetic individuals and several factors, including hypertension, contribute to the high prevalence of cardiovascular diseases. The two-way relationship between these diseases and anxiety disorders has been studied for decades (19). Even though death anxiety was higher in individuals with chronic diabetes, chronic hypertension or chronic coronary diseases, it was not related to other chronic diseases, probably because anxiety has a two-way relationship with these diseases.

Death anxiety was lower for smokers. It is possible that smoking decreases stress level by reducing the level of arousal. However, death anxiety was higher for alcohol users. A related theory indicates that individuals with high anxiety sensitivity resort to using alcohol to suppress negative emotional experiences (20). 
Understandably, high anxiety sensitivity causes death anxiety.

\section{Relationship between Perceived Pain and Sociodemographic Data}

The underlying causes for the cognitive modulations of pain have not yet been fully understood. Pain perception is a subjective state determined through expectations and learning modification (21), and it is expected to be affected by personal factors. Our study observed a decrease in pain score with a higher education level. Therefore, education level could be a significant predictor for pain.

Pain score increased with ageing and it was higher in females. In general, it has been reported that perceived $\mathrm{PI}$ varies with gender and advanced age (22)

Perceived pain was lower in smokers and alcohol users-a finding non-concordant with other studies. Notably, alcohol was observed not to have a pain-reducing effect. However, chronic pain is higher in chronic alcoholics (23). Nevertheless, the patients included in our study were not alcohol consumers at an addictive level. Therefore, the relationship between alcohol and pain concerning causality should be studied in more detail in the elderly. It has been put forth that smoking results in perceiving PI more in children and adults (24). However, it is unclear how smoking affects pain

\section{REFERENCES}

1. World Health Organization. World report on ageing and health. Geneva: WHO; 2015. pp:25-45. [Internet] Available from: https://apps.who.int/iris/ bitstream/handle/10665/186463/9789240694811_ e n g.p p f; j s e s s i o n i d = 5122 F 9 C $2 \overline{1}$ 36EB 19B15B0448E62A347ED? sequence $=1$. Accessed: 31.10.2019.

2. World Health Organization. Global Health And Aging. 2011. pp:2. [Internet] Available from:https://www.who.int/ageing/ publications/global_health.pdf.Accessed: 31.10.2019.

3. Turkish Statistical Institute. Statistics of Elderly perception. This pain perception is considered to be probably related to the effect of smoking on nicotinic Ach receptors in SSS. Notably, chronic smoking opens paths in these receptors through desensitisation. However, the different result for the elderly in our study could be related to the reduced number of nicotinic Ach receptors with ageing (25).

\section{Limitations}

The major limitations of the present study were that it lacked a control group and that elderly individuals with the same disease were not examined. However, separate evaluations were performed based on diagnoses. Moreover, a causality relationship could not be discussed owing to the cross-sectional nature of the study.

In conclusion, the level of education, gender, smoking and alcohol use are factors that affect death anxiety. Education level, age, gender, alcohol use and smoking are sociodemographic factors that influence perceived pain. A positive relationship is observed between death anxiety and perceived pain in elderly individuals. The pain had the strongest relationship with the anxiety caused by AmD. The prognosis of the individuals may be affected adversely if this anxiety is not treated in the elderly because anxiety and pain adversely affect the quality of life. Nonetheless, further comparative studies involving a wide range of patients with similar diagnoses are warranted.

population. 2018. pp:1-2. [Internet] Available from: https://biruni.tuik.gov.tr/yayin/views/visitorPages/ index.zul. Accessed: 21.11.2019.

4. Oker K, Schmelowszky Á, Reinhardt M. Comparison of the Relationship Between Death Anxiety and Depressive and Anxiety Symptoms Among Norwegian and Turkish Female Psychology Students. OMEGA-Journal of Death and Dying 2019; 8:online first. (PMID: 31393217).

5. Akgün S, Bakar C, Budakoğlu i. Trends of Elderly Population in the World and Turkey:Problems and Recommendations. Turkish Journal of Geriatrics 2004;7(2):105-10.[Internet] Available from:http:// 
geriatri.dergisi.org/uploads/pdf/pdf_TJG_212.pdf. Accessed: 31.10.2019.

6. Herr KA, Garand L. Assessment and measurement of pain in older adults. Clinics in geriatric medicine 2001;17(3):457-78. (PMID:11459715)

7. Ferrell BA, Stein WM, Beck JC. The Geriatric Pain Measure: validity, reliability and factor analysis. Journal of the American Geriatrics Society 2000;48(12):166973. (PMID:11129760).

8. Wiech K, Tracey I. The influence of negative emotions on pain: behavioral effects and neural mechanisms. Neuroimage 2009;47(3):987-94. (PMID:19481610).

9. Güngen C, Ertan T, Eker E, et al. Reliability and validity of the standardized Mini Mental State Examination in the diagnosis of mild dementia in Turkish population. Turkish Journal of Psychiatry 2002;13(4):273-81. (PMID:12794644).

10. Sarıkaya Y, Baloğlu M. The development and psychometric properties of the Turkish death anxiety scale (TDAS). Death studies 2016;40(7):419-31. (PMID: 26933746).

11. Dursun G, Bektas H. Cultural Validation and Reliability of the Turkish Version of the Geriatric Pain Measure in the Elderly. PAIN Practice 2017;17(4):505-513. (PMID: 27370573)

12. Suhail K, Akram S. Correlates of death anxiety in Pakistan. Death stud 2002;26(1):39-50.94. (PMID:11865882).

13. Metzger S, Poliakov B, Lautenbacher S. Differential effects of experimentally induced anxiety and fear on pain: the role of anxiety sensitivity. J Pain Res 2019;12:1791. (PMID:31239757).

14. Malt EA, Ursin H. Mutilation anxiety differs among females with fibromyalgia and functional dyspepsia and population controls. J psychosom res 2003;54(6):523-31. (PMID:12781306).

15. Zvolensky MJ, Vujanovic AA, Bernstein A, Leyro T. Distress tolerance: Theory, measurement, and relations to psychopathology. Current Directions in Psychological Science 2010;19(6):406-10. [Internet] Available from:https://journals.sagepub. com/doi/10.1177/0963721410388642. Accessed: 06.11.2019
16. Bjelland I, Krokstad S, Mykletun A, Dahl AA, Tell GS, Tambs K. Does a higher educational level protect against anxiety and depression? The HUNT study. SocSci Med 2008;66(6):1334-45. (PMID:18234406).

17. Surall V, Steppacher I. How to Deal with Death: An Empirical Path Analysis of a Simplified Model of Death Anxiety. OMEGA-Journal of Death and Dying 2018: Online first. (PMID:30373472).

18. Craske MG. Origins of phobias and anxiety disorders: Why more women than men? In: Michelle G. Craske (eds). Origins of phobias and anxiety disorders. 1st edition. Elsevier, Kidlington, Oxford, UK; 2003 pp:1235

19. Player MS, Peterson LE. Anxiety disorders, hypertension, and cardiovascular risk: a review. The IntJ Psychiatry Med 2011;41(4):365-77. (PMID:22238841).

20. Stewart $\mathrm{SH}, \mathrm{Pihl} \mathrm{RO}$. Effects of alcohol administration on psychophysiological and subjective-emotional responses to aversive stimulation in anxietysensitive women. Psychology of Addictive Behaviors. 1994;8(1):29. [Internet] Available from:https:// psycnet.apa.org/doiLanding?doi=10.1037\%2F0893164X.8.1.29. Accessed: 06.11.2019

21. Wiech K. Deconstructing the sensation of pain: the influence of cognitive processes on pain perception. Science 2016;354(6312):584-87. (PMID:27811269).

22. Côté P, Cassidy JD, Carroll L. The factors associated with neck pain and its related disability in the Saskatchewan population. Spine 2000;25(9):110917. (PMID:10788856).

23. Sheu R, Lussier D, Rosenblum A, et al. Prevalence and characteristics of chronic pain in patients admitted to an outpatient drug and alcohol treatment program. Pain Med 2008;9(7):911-17. (PMID:18346064).

24. Hanci $V$, Kiraz HA, Ömür D, et al. Effects of smoking on venous cannulation pain: a randomized prospective trial. Rev bras anestesiol. 2015;65(1):4750. (PMID:25497749).

25. Zanardi A, Leo G, Biagini G, Zoli M. Nicotine and neurodegeneration in ageing. Toxicol Lett 2002;127(1-3):207-15.(PMID:12052660). 